\title{
LER, OUVIR E VER. \\ A REVOLUÇÃO DOCUMENTAL NA PESQUISA HISTÓRICA: UMA ABORDAGEM DAS FORMAS DA CONSTRUÇÃO DA HISTÓRIA
}

William Reis Meirelles ${ }^{1}$

RESUMO:

O artigo apresenta uma reflexão sobre a revolução documental na pesquisa histórica.

PALAVRAS-CHAVE:

documento histórico, construção da história.

"A única generalização cem por cento segura sobre a história é aquela que diz que enquanto houver raça humana haverá história". Eric J. Hobsbawm

Para Fustel de Coulanges a "[.. . ].única habilidade (do historiador) consiste em tirar dos documentos tudo o que eles contém e em não acrescentar nada do que ele não contém. 0 melhor historiador é aquele que se mantém o mais próximo possível dos textos" (COULANGES apud LE GOFE, 1990, p. 536).

Foram os positivistas, como Coulanges, que transformaram o documento escrito em fundamento do fato histórico.

O termo documento vem do latim documentmm, que por sua vez vem de docere, ensinar. Com o passar do tempo o significado do termo evoluiu para significar prova, vocábulo

1 Professor Associado do Departamento de História da Universidade Estadual de Londrina. Doutor em História e Sociedade pela UNESP.wreism@uel.br. 
fartamente utilizado na linguagem jurídica e legislativa. [Cartório de títulos e documentos]

No início do século XIX aparece com o sentido de testemunho histórico, sendo o documento escrito a sua expressão material, ou ainda, a escrita transformou-se no suporte desse testemunho [a idéia das leis escritas]. Não vamos aqui fazer a crítica ao pensamento positivista, pois este não é nosso objetivo neste momento.

Retomando a citação de Coulanges que vem de encontro ao objetivo desta apresentação, podemos constatar que o texto escrito tornou-se, por muito tempo, a única fonte possível para o trabalho do historiador. $\mathrm{O}$ documento escrito impôs-se como a única maneira ou o único caminho para se atingir a verdade no passado.

Mas, podemos perceber que o historiador, na aula inaugural da Universidade de Strasbourg, proferida no ano de 1862, ainda que naquelas palavras reafirmasse os pressupostos do positivismo, apontava para outros focos ante a impossibilidade da existência de documentos escritos.

Chesnaux ao criticar os historiadores positivistas e os "positivistas" em geral, nos mostra que:

"[...]. os fatos históricos são contraditórios como o próprio decorrer da história; eles são percebidos diferentemente (porque diferentemente ocultados) segundo o tempo, o lugar, a classe, a ideologia. Por outro lado, escapam à experimentação direta por sua natureza passada; são suscetíveis apenas de aproximações progressivas, sempre mais próximas do real, nunca acabadas nem completas" (CHESNAUX, 1995, p. 67).

Para Coulanges:

"[...] onde faltam os monumentos escritos, deve a história demandar as línguas mortas, os seus segredos... Deve escrutar as fábulas, os 
mitos, os sonhos da imaginação... Onde o homem passou, onde deixou qualquer marca da sua vida e da sua inteligência, aí está a história" (LEGOFF, 1990, p. 539).

Por estas palavras podemos perceber as inquietações e as dúvidas que atingiam o historiador. Ao constatar que nem sempre é possível recuperar o passado através de testemunhos escritos, provavelmente, ele se dava conta de que era possível recuperar o passado por outros meios, por aquelas "marcas" que o homem deixou por onde passou.

A inexistência dos "monumentos escritos" como falava Coulanges era, certamente, o dilema constante com que topava o historiador ao longo do seu trabalho. Esse problema nos conduz a uma questão, sempre atual, o de como preencher as lacunas, recuperar a presença dos seres humanos quando eles não deixaram rastros escritos?

"Fábulas, mitos, sonhos da imaginação..." são algumas pistas que o historiador francês nos aponta e que entendemos como clara referência de que o mundo real não é constituído exclusivamente pela sua expressão material, mas é, também, pelo imaginário que contém.

Para Le Goff e Nora, os historiadores ao tomar consciência do relativismo de sua ciência, levou-os a reformular e redefinir suas práticas e o ponto de partida foi o de que a "[...]. História não é o absoluto dos historiadores do passado, providencialistas ou positivistas, mas o produto de uma situação, de uma história" (LE GOFF ; NORA, 1979, p. 12)

A história como ciência, ainda segundo esses autores, possui apenas um

"[...] único termo para seu objeto e para si própria, que oscila entre a história vivida e a história construída, sofrida e fabricada, obriga os historiadores, já conscientes dessa relação original, a se 
interrogarem novamente sobre os fundamentos epistemológicos de sua disciplina" (LE GOFF ; NORA, 1979, p. 12)

Na apresentação do livro Faire I'Histoire (1974), Le Goff e Nora, lamentam não poder apresentar os "objetos típicos dos novos apetites da história", limitando-se a apresentar apenas uma pequena amostragem que consideram significativa:

"Reservamos então alguns objetos paradoxais, seja pela sua aparente intemporalidade, como o clima, o corpo, o mito, a festa; seja pela sua inclinação para a história imóvel ou oculta: a mentalidade, os jovens; seja por suas ligações com as novas ciências e seu desvio em direção da história: o inconsciente da psicanálise, a língua da lingüística moderna, a imagem cinematográfica, as sondagens de opinião pública; seja por sua trivialidade novamente promovida à dignidade da história: a cozinha, que por sua vez testemunha a favor de dois setores de importância crescente no campo da história, o da civilização material e o das técnicas; seja, enfim, pela escandalosa mudança de ótica que infligimos a um objeto: o livro, considerado como um produto de massa e não mais como produção de elite, exemplo particular da revolução quantitativa em história" (LE GOFF; NORA, 1979, p. 14).

Não é novidade relembrar o intenso questionamento que vem ocorrendo, nas últimas décadas, sobre os sistemas tradicionais da explicação histórica. O próprio conceito de documento histórico passou por mudanças ampliando-se e passando a envolver,

“[...] todas as fontes de conhecimento histórico (diretas ou indiretas), ou seja, toda informação (no sentido da teoria da informação) sobre o passado humano, onde quer que se encontre essa informação, juntamente com os modos de transmitir essa informação (canais de informação)" (TOPOLSKY, 1982, p. 300). 
O desafio que hoje se coloca para o historiador, leva-o a desviar seu olhar em direção de novos caminhos, trilhar o desconhecido, o incerto, o impreciso e o indeterminado, como forma de superar os "velhos" paradigmas, insuficientes para dar conta da complexidade e da multiplicidade de abordagens possíveis do real e do imaginário, os quais não podem ser separados, pois seria inútil atribuir a qualquer um a função privilegiada de referencial.

Como nos mostra Raymond Williams:

"Numa economia capitalista moderna, com seu tipo característico de ordem social, as instituições culturais da edição de livros, revistas e jornais, do cinema, do rádio, da televisão e das gravadoras de disco não são mais marginais ou sem importância como nas fases iniciais de mercado, porém, tanto em si mesmas como por seu freqüente entrelaçamento e integração com outras instituições produtivas, são partes da organização social e econômica global de maneira bastante generalizada e difundida" (WILLIAMS, 1992, p. 53-4).

Nas últimas décadas o campo do historiador expandiuse a uma velocidade vertiginosa. Em recente balanço historiográfico da Escola dos Annales, François Dosse aponta no seu livro: História em Migalhas que:

"[...] nos meios de comunicação de massa, a informação renova-se a cada dia e um conjunto de acontecimentos ao mesmo tempo rápido e urgente desenvolve-se sobre a vasta cena mundial; isso nos oferece a imagem de uma história que se acelera ao mesmo tempo que nos escapa" (DOSSE, 1992, p. 14).

O círculo dos historiadores profissionais aos poucos foi sendo ultrapassado pelo imperativo da História:

"Não são apenas os antigos marginalizados da história oficial que 
alimentam o desejo de recuperar o seu passado desaparecido. São todos os corpos constituídos, intelectuais ou não, que a exemplo das etnias e das minorias sociais, experimentam o desejo de partir para a pesquisa da sua própria constituição, de reencontrar as suas origens" (NORA apud DE DECCA, 1992, p. 133).

Nesse movimento de recuperação do passado pelos corpos constituídos da sociedade, multiplicaram-se os centros e instituições destinados à guarda de documentos históricos, não apenas os escritos, mas tudo aquilo que de alguma forma esteja identificado com um determinado grupo ou, ainda, construindo os novos documentos que recuperam o passado, a exemplo do que ocorre com os arquivos dedicados à história oral.

Assim, a apropriação da História por múltiplos grupos sociais, reivindicando para si aquilo que por muito tempo se constituiu campo exclusivo do saber do historiador, levou-nos a uma ampla discussão sobre questões relacionadas à preservação dos chamados suportes de memória.

Com o advento das inovações surgidas nas últimas décadas do século passado e a aceleração produzida pelos aparatos de reprodutibilidade técnica (imprensa, fotografia, fita de áudio, cinema, vídeo, multimídia), multiplicaram-se quase que infinitamente as possibilidades de registro de memórias.

Em conseqüência, grupos não participantes de instâncias de poder passaram a se apropriar dessas inovações, das novas linguagens surgidas na mídia, rompendo com o monopólio da fabricação de versões socialmente verossímeis, de histórias unas, de verdade única.

Sob este aspecto, é necessário, ainda, levar em conta na nossa análise aquelas fontes que foram privilegiadas em outras interpretações e construções históricas, especialmente aquelas que se consolidaram delineando um influente sistema de representação, impondo-se como linhas de pensamento 
hegemônico e, em conseqüência, predominando sobre outras interpretações possíveis da realidade brasileira.

Sob este aspecto, Marc Ferro aponta com propriedade que:

"Controlar o passado ajuda a dominar o presente e a legitimar tanto as dominações como as rebeldias. Ora, são os poderes dominantes: Estados, Igrejas, partidos políticos ou interesses privados que possuem ou financiam livros didáticos ou histórias em quadrinhos, filmes e programas de televisão. Cada vez mais eles entregam a cada um e a todos um passado uniforme. E surge a revolta entre aqueles cuja história é proibida" (FERRO, 1983, p. 11).

Para concluir vale lembrar o que Hobsbawm escreveu sobre o nosso século em seu livro A Era dos Extremos:

"Meu objetivo é compreender e explicar como as coisas deram no que deram e como elas se relacionam entre si. Para qualquer pessoa de minha idade que tenha vivido todo o Breve Século XX ou a maior parte dele, isso é também, inevitavelmente uma empresa autobiográfica. Trata-se de comentar, ampliar (e corrigir) nossas próprias memórias. $\mathrm{E}$ falamos como homens e mulheres de determinado tempo e lugar, envolvidos de diversas maneiras em sua história como atores de seus dramas - por mais insignificantes que sejam nossos papéis -, como observadores de nossa época e, igualmente, como pessoas cujas opiniões sobre o século foram formadas pelo que viemos a considerar acontecimentos cruciais. Somos parte deste século. Ele é parte de nós."

"Que não o esqueçam os leitores que pertencem a outra era, por exemplo os estudantes que estão ingressando na universidade no momento em que escrevo e para quem até a Guerra do Vietnã é pré-história" (HOBSBAWM, 1995, p. 13). 


\section{Bibliografia}

COULANGES, Fustel de. Une leçon d'ouverture et quelques fragments inedits. Apud LE GOFF, Jacques. História e Memória. Campinas: UNICAMP,1990.

CHESNAUX, Jean. Devemos fazer tabula rasa do passado? São Paulo: Ática, 1995.

LE GOFF, Jacques ; NORA, Pierre. História: novos problemas, 2. ed. São Paulo: Martins Fontes, 1979.

TOPOLSKY, Jerzy. Metodologia de la história. Madrid: Cátedra, 1982.

WILLIAMS, Raymond. Cultura. Rio de Janeiro: Paz e Terra, 1992.

DOSSE, François. História em Migalhas. Campinas: UNICAMP, 1992.

NORA, Pierre. Les Liex de Mémoire. apud DE DECCA, Edgar S. Memória e Cidadania. In: SÃO PAULO (cidade). Secretaria Municipal de Cultura. Departamento de Patrimônio Histórico. O Direito à Memória: patrimônio histórico e cidadania. São Paulo: DPH, 1992.

FERRO, Marc. A manipulação da história no ensino e nos meios de comunicação. São Paulo: IBRASA, 1983. Tradução do original: Comment on raconte I'histoire aux enfants á travers le monde entier. Paris: Payot,1981.

HOBSBAWM, E. J. Era dos Extremos: o breve século XX: 1914-1991. São Paulo: Cia. das Letras, 1995.

\section{ABSTRACT:}

The article presents a reflection about the documental revolution in the historical research.

KEY WORDS:

historical document, construction of the history. 